BMJ Open Diabetes Research \& Care

\title{
Evaluation of statin prescriptions in type 2 diabetes: India Heart Watch-2
}

\author{
Rajeev Gupta, ${ }^{1}$ Sailesh Lodha, ${ }^{1}$ Krishna K Sharma, ${ }^{2}$ Surendra K Sharma, ${ }^{3}$ \\ Sunil Gupta, ${ }^{4}$ Arthur J Asirvatham, ${ }^{5}$ Bhupendra N Mahanta, ${ }^{6}$ Anuj Maheshwari, ${ }^{7}$ \\ Dinesh C Sharma, ${ }^{8}$ Anand S Meenawat, ${ }^{9}$ Raghubir S Khedar ${ }^{1}$
}

To cite: Gupta R, Lodha S, Sharma KK, et al. Evaluation of statin prescriptions in type 2 diabetes: India Heart Watch-2. BMJ Open Diabetes Research and Care 2016:4: e000275. doi:10.1136/ bmjdrc-2016-000275

Received 27 May 2016 Revised 20 July 2016 Accepted 27 July 2016

\section{CrossMark}

For numbered affiliations see end of article.

Correspondence to Dr Rajeev Gupta; rajeevgg@gmail.com

\section{ABSTRACT}

Background: Contemporary treatment guidelines advise statin use in all patients with diabetes for reducing coronary risk. Use of statins in patients with type 2 diabetes has not been reported from India.

Methods: We performed a multisite $(n=9)$ registrybased study among internists $(n=3)$, diabetologists $(n=3)$, and endocrinologists $(n=3)$ across India to determine prescriptions of statins in patients with type 2 diabetes. Demographic and clinical details were obtained and prescriptions were audited for various medications with a focus on statins. Details of type of statin and dosage form (low, moderate, and high) were obtained. Patients were divided into categories based on presence of cardiovascular risk into low (no risk factors, $n=1506$ ), medium ( $\geq 1$ risk factor, $n=5425$ ), and high (with vascular disease, $n=1769$ ). Descriptive statistics are presented.

Results: Prescription details were available in 8699 (men 5292, women 3407). Statins were prescribed in $55.2 \%$ and fibrates in $9.2 \%$. Statin prescription was significantly greater among diabetologists $(64.4 \%)$ compared with internists $(n=53.3 \%)$ and endocrinologists $(46.8 \% ; p<0.001)$. Atorvastatin was prescribed in $74.1 \%$, rosuvastatin in $29.2 \%$, and others in $3.0 \%$. Statin prescriptions were lower in women $(52.1 \%)$ versus men $(57.2 \% ; p<0.001)$ and in patients aged $<40$ years $(34.3 \%)$, versus those aged $40-49$ $(49.7 \%), 50-59(60.1 \%)$, and $\geq 60$ years $(62.2 \%$; $\mathrm{p}<0.001)$. Low-dose statins were prescribed in $1.9 \%$, moderate dose in $85.4 \%$, and high dose in $12.7 \%$. Statin prescriptions were greater in the high-risk group $(58.0 \%)$ compared with those in the medium-risk $(53.8 \%)$ and low-risk $(56.8 \%)$ groups $(p<0.001)$. High-dose statin prescriptions were similar in the highrisk $(14.5 \%)$, medium-risk (11.8\%), and low-risk $(13.5 \%)$ groups $(p=0.31)$.

Conclusions: Statins are prescribed in only half of the clinic-based patients in India with type 2 diabetes. Prescription of high-dose statins is very low.

\section{INTRODUCTION}

Diabetes is an epidemic in India. ${ }^{1}$ It is also associated with a greater prevalence of macrovascular and microvascular disease and these patients have a higher long-term mortality as compared with patients in developed countries. ${ }^{2}{ }^{3}$ Multiple factors are responsible

\section{Key messages}

- There are no contemporary data on statin prescriptions among patients with type 2 diabetes in India.

- In a multisite study in India, we observed suboptimal prescription of statins in patients with diabetes. A prescription of high-dose statins was low in all patients with diabetes, including those at high risk.

- Statin prescriptions were significantly less by endocrinologists and physicians compared with diabetologists.

for greater morbidity and mortality from diabetes in India and include low awareness, treatment, and control of glycemia in patients with diabetes. ${ }^{45}$ Greater prevalence and low awareness, treatment, and control of cardiovascular risk factors (smoking, hypertension, dyslipidemia, and unhealthy lifestyles), especially in lower socioeconomic status patients, is also important. ${ }^{6}$

Control of cardiovascular risk factors such as hypertension and hypercholesterolemia in patients with diabetes can prevent complications. It has been reported that appropriate use of statins can prevent symptomatic coronary heart disease as well as acute coronary events in patients with type 2 diabetes in all populations including South Asians. ${ }^{7} 8$ Patients with type 2 diabetes have a longterm risk of cardiovascular mortality similar to patients without diabetes and overt cardiovascular disease. ${ }^{8-12}$ Based on these epidemiological observations and primary prevention trials, many international guidelines recommend routine use of statins in patients with type 2 diabetes. ${ }^{8}{ }^{13-15}$ The American College of Cardiology/American Heart Association (ACC/AHA) 2013 statement classified diabetes as a coronary risk equivalent and recommended high-dose statin therapy in all patients with diabetes. Diabetes registries in developed countries, for example, the Swedish National Diabetes Register, have reported a high use of statins 
in patients with type 2 diabetes. ${ }^{16}$ No similar data are available from developing countries, including India. Previous studies that reported treatment patterns in type 2 diabetes in India were published before the recent recommendations ${ }^{17-20}$ and a review reported suboptimal quality of diabetes management in India. ${ }^{21}$ Therefore, to document the extent of prescriptions of statins and their types in patients with type 2 diabetes and to correlate this with vascular risk status of these patients, we performed a multisite registry-based study.

\section{METHODS}

We performed a multisite $(n=9)$ registry-based study in eight cities across India to determine the prescription pattern of statins in patients with type 2 diabetes. The Institutional Ethics Committee at the central coordinating center at Jaipur, India, approved the study. Requirement of informed consent from each patient was waived by the Ethics Committee because anonymized data were used for analyses. We obtained data on successive patients attending the outpatient department at respective centers until the target of 500 patients was reached at each site. A larger sample size was available at the primary site where the pro forma was piloted. ${ }^{20}$

Demographic and clinical details were obtained that were similar to the previous India Heart Watch study. ${ }^{4}$ An abbreviated version useful for a disease registry was used in the present study. ${ }^{20}$ Sociodemographic factors were education, occupation, and socioeconomic status and lifestyle factors included details of smoking and tobacco use, physical activity patterns and diet. Details of concomitant risk factors-overweight or obesity (body mass index $\geq 25 \mathrm{~kg} / \mathrm{m}^{2}$ ), hypertension, hypercholesterolemia (total cholesterol $\geq 200 \mathrm{mg} / \mathrm{dL}$ ), hypertriglyceridemia (triglycerides $\geq 150 \mathrm{mg} / \mathrm{dL}$ ), and low high-density lipoprotein (HDL) cholesterol $(<40 \mathrm{mg} / \mathrm{dL}$ in men, $<50 \mathrm{mg} / \mathrm{dL}$ in women) - as well as duration of diabetes were also obtained. Presence of microvascular diseases was ascertained from medical records with a focus on diabetic retinopathy, chronic renal disease (serum creatinine $\geq 2.0 \mathrm{mg} / \mathrm{dL}$ ), and overt diabetic foot disease. We did not obtain details of the presence of microalbuminuria, proteinuria, albumin-creatinine ratio, or anklebrachial index due to lack of uniform data at all sites. Presence of macrovascular disease was obtained from the patients and included history of overt coronary heart disease, history of stroke, or symptomatic peripheral arterial disease with claudication.

Physicians were divided by specialization into specific type of care provider as internists $(n=3)$, diabetologists (internists with primary interest in diabetes, $n=3$ ), and board-certified endocrinologists $(n=3)$. Patients were also subdivided accordingly into internists $(n=2301)$, diabetologists $(n=3299)$, and endocrinologists $(n=3099)$. Patients were also categorized based on the presence of cardiovascular risk into low, medium, and high risk. Risk factors other than diabetes were used in classification and were either smoking or tobacco use, hypertension, or hypercholesterolemia. Details of overt microvascular disease (retinopathy, chronic renal failure, serum creatinine $\geq 2.0 \mathrm{mg} / \mathrm{dL}$, diabetic foot) or macrovascular disease (coronary heart disease, history or presence of stroke, symptomatic peripheral vascular disease) were also recorded. Low-risk patients had no risk factor other than diabetes $(n=1506)$, moderate-risk patients had any one of these risk factors $(n=5425)$, and high-risk patients were participants with microvascular or macrovascular disease $(n=1769)$.

Prescriptions were audited for various medications including lipid-lowering, antidiabetic, and antihypertensive drugs. We obtained details of type of statin (atorvastatin, rosuvastatin, other statins) and daily dose in $\mathrm{mg} /$ day. Frequency of prescription of fibrates (fenofibrate) was also obtained. Low-dose statin prescription was defined as atorvastatin $<10 \mathrm{mg} /$ day, simvastatin $<20 \mathrm{mg}$ / day, or rosuvastatin $<5 \mathrm{mg}$ /day; moderate dose as atorvastatin $10-20 \mathrm{mg} /$ day, simvastatin $20-40 \mathrm{mg} /$ day, or rosuvastatin $5-10 \mathrm{mg} /$ day; and high dose as atorvastatin $40-80 \mathrm{mg} /$ day or rosuvastatin $20-40 \mathrm{mg}$ /day according to the ACC/AHA guidelines. ${ }^{8}$

Statistical analyses: All the data were computerized and quality checks were performed to reduce duplicate and redundant data. Statistical analyses were performed using SPSS for Windows (SPSS, V.13.0). Descriptive statistics are presented with unadjusted data and proportions. Intergroup comparisons were performed using $\chi^{2}$ test. p Values $<0.05$ were considered significant.

\section{RESULTS}

We obtained detailed prescriptions for 8699 patients with type 2 diabetes (men 5292, women 3407). Recruitment at different sites was Jaipur (3 sites, $\mathrm{n}=3714,42.7 \%$ ), Nagpur $(\mathrm{n}=1536,17.7 \%)$, Madurai $(\mathrm{n}=971,11.2 \%)$, Dibrugarh $(\mathrm{n}=796,9.2 \%)$, Lucknow $(\mathrm{n}=792,9.1 \%)$, Udaipur ( $\mathrm{n}=548,6.3 \%)$, and Jodhpur $(\mathrm{n}=342,3.9 \%)$. Patients were subdivided according to level of care into the internists' group $(\mathrm{n}=2301,26.5 \%)$, diabetologists' group $(\mathrm{n}=3299,37.9 \%)$, and endocrinologists' group $(\mathrm{n}=3099,35.6 \%)$. Demographic and clinical details of the study participants are shown in table 1 . Twelve per cent of the study participants were $<40$ years of age. Most of the patients had diabetes for $>2$ years and a third for $>5$ years. Risk factor details were available for most patients (table 1). Smoking and/or tobacco use was one-fifth while moderate-to-high physical activity in less than half. Hypertension was present in $51.5 \%$, with total cholesterol $\geq 200 \mathrm{mg} / \mathrm{dL}$ in $34.9 \%$, lowdensity lipoprotein cholesterol $\geq 100 \mathrm{mg} / \mathrm{dL}$ in $50.0 \%$, triglycerides $\geq 150 \mathrm{mg} / \mathrm{dL}$ in $35.2 \%$, and low HDL cholesterol in $48.9 \%$. Hypothyroidism was present in $9.2 \%$ and was more in women $(13.0 \%)$. Coronary heart disease was present in $15.4 \%$ and others (stroke, large vessel peripheral arterial disease in 5.2\% while microvascular complications such as retinopathy, 
Table 1 Demographic and clinical characteristics of the study cohort

\begin{tabular}{|c|c|c|c|c|c|}
\hline Variable & $\begin{array}{l}\text { Numbers with data } \\
\text { Total, men/women }\end{array}$ & $\begin{array}{l}\text { Total } \\
(\mathrm{N}=8699)\end{array}$ & $\begin{array}{l}\text { Men } \\
(\mathrm{N}=5292)\end{array}$ & $\begin{array}{l}\text { Women } \\
(\mathrm{N}=3407)\end{array}$ & $\begin{array}{l}\text { X2 test } p \text { value } \\
\text { (male/female } \\
\text { differences) }\end{array}$ \\
\hline \multicolumn{6}{|l|}{ Age groups } \\
\hline$<40$ & $8699,5292 / 3407$ & $1016(11.7)$ & $625(11.8)$ & $391(11.5)$ & 0.635 \\
\hline $40-49$ & & 2288 (26.3) & $1385(26.2)$ & $903(26.5)$ & 0.731 \\
\hline $50-59$ & & 2815 (32.3) & $1728(32.6)$ & 1087 (31.9) & 0.466 \\
\hline $60+$ & & $2580(29.7)$ & 1554 (29.3) & $1026(30.1)$ & 0.558 \\
\hline \multicolumn{6}{|l|}{ Socioeconomic status } \\
\hline Low & $6346,3766 / 2580$ & 2239 (35.3) & $1345(35.7)$ & $894(34.6)$ & 0.384 \\
\hline Middle & & $2516(39.6)$ & 1499 (39.8) & 1017 (39.4) & 0.758 \\
\hline High & & $1591(25.1)$ & $922(24.5)$ & $669(25.9)$ & 0.191 \\
\hline \multicolumn{6}{|l|}{ Diabetes duration (year) } \\
\hline$<2$ & $5081,3027 / 2054$ & $948(18.6)$ & $554(18.3)$ & 394 (19.2) & 0.429 \\
\hline $2-5$ & & $2263(44.5)$ & $1340(44.2)$ & 923 (44.9) & 0.638 \\
\hline$>5$ & & $1870(36.8)$ & $1133(37.4)$ & 737 (35.9) & 0.261 \\
\hline Smoking/tobacco use & $7695,4678 / 3017$ & 1633 (21.2) & $1201(25.6)$ & 432 (14.3) & $<0.001$ \\
\hline Physical activity & $7029,4372 / 2657$ & $3150(44.8)$ & $2122(48.5)$ & $1028(38.7)$ & $<0.001$ \\
\hline Obesity, BMI $\geq 25 \mathrm{~kg} / \mathrm{m}^{2}$ & $8699,5292 / 3407$ & 3070 (35.3) & 1773 (33.5) & 1293 (37.9) & $<0.001$ \\
\hline Hypertension & $8673,5275 / 3398$ & $4464(51.5)$ & $2583(48.9)$ & $1881(55.3)$ & $<0.001$ \\
\hline Cholesterol $\geq 200 \mathrm{mg} / \mathrm{dL}$ & $3979,2469 / 1510$ & $1390(34.9)$ & $824(33.4)$ & $566(37.5)$ & 0.008 \\
\hline LDL cholesterol $\geq 100 \mathrm{mg} / \mathrm{dL}$ & $3979,2469 / 1510$ & 1989 (50.0) & 1193 (48.3) & 796 (52.7) & 0.007 \\
\hline Triglycerides $\geq 150 \mathrm{mg} / \mathrm{dL}$ & $3979,2469 / 1510$ & 1403 (35.2) & 866 (35.0) & $537(35.5)$ & 0.754 \\
\hline $\mathrm{HDL}<40 / 50 \mathrm{mg} / \mathrm{dL}$ & $3979,2469 / 1510$ & 1945 (48.9) & $1025(41.5)$ & 920 (60.9) & 0.001 \\
\hline \multicolumn{6}{|l|}{ Macrovascular complications } \\
\hline Coronary heart disease & $7131,4391 / 2740$ & 1099 (15.4) & $720(16.4)$ & $379(13.8)$ & 0.003 \\
\hline Others (stroke, PAD) & & $372(5.2)$ & $232(8.5)$ & $140(5.1)$ & 0.743 \\
\hline \multicolumn{6}{|l|}{ Microvascular diseases } \\
\hline Retinopathy & $4851,2992 / 1859$ & $298(6.1)$ & $183(6.1)$ & $115(6.1)$ & 0.994 \\
\hline Others & & $670(13.9)$ & $424(14.2)$ & $246(13.2)$ & 0.357 \\
\hline Hypothyroidism & 5423, 3289/2134 & $500(9.2)$ & $222(6.7)$ & 278 (13.0) & $<0.001$ \\
\hline $\begin{array}{l}\text { Chronic renal disease } \\
\text { (serum creatinine } \geq 2.0 \mathrm{mg} / \mathrm{dL} \text { ) }\end{array}$ & $6381,3915 / 2466$ & $356(5.6)$ & $267(6.8)$ & $89(3.6)$ & $<0.001$ \\
\hline
\end{tabular}

Numbers in parentheses are percent.

BMI, body mass index; HDL, high-density lipoprotein; LDL, low-density lipoprotein; PAD, peripheral arterial disease.

diabetic foot or advanced chronic renal disease (creatinine $\geq 2.0 \mathrm{mg} / \mathrm{dL}$ ) was in $6.1 \%, 13.9 \%$, and $6.8 \%$, respectively.

Use of lipid-lowering drugs and others is shown in table 2. Statins were prescribed in $4802(55.2 \%)$ patients, significantly more in men $(57.2 \%)$ compared with women $(52.1 \% ; \mathrm{p}<0.001)$. Use of fibrates was low $(9.2 \%)$. Insulins were used in $15.8 \%$, more in men $(16.8 \%)$ as compared with women $(14.2 ; \mathrm{p}=0.016)$. Use of antihypertensive drugs is also shown in table 2 . The most frequently used drugs were renin angiotensin system blockers, ACE inhibitors, or angiotensin receptor blockers in $36.4 \%$ of patients, while diuretics $(31.8 \%)$, B-blockers $(27.6 \%)$, and calcium channel blockers $(23.7 \%)$ were prescribed in lesser proportions.

Statin prescription was significantly greater by diabetologists $(\mathrm{n}=2126 / 3299,64.4 \%)$ compared with internists $(\mathrm{n}=1227 / 2301,53.3 \%)$ and endocrinologists $(\mathrm{n}=1449 /$ $3099,46.8 \%$; $<0.001 ;$ table 2). It was also lower in patients $<40$ years of age $(34.3 \%)$, compared with those aged $40-49$ years $(49.7 \%), \quad 50-59$ years $(60.1 \%)$, or $\geq 60$ years $(62.2 \% ; \mathrm{p}<0.001$; figure 1$)$. Statin prescriptions were significantly greater in high-risk patients $(58.0 \%)$ compared with medium-risk (53.8\%) and low-risk $(56.8 \%)$ patients $(\mathrm{p}<0.001$; table 2$)$.

Atorvastatin was the most prescribed statin $(n=3560$, $74.1 \%$ of statin prescriptions), as compared with rosuvastatin $(\mathrm{n}=1098,22.9 \%)$ or others (simvastatin or pitavastatin; $\mathrm{n}=144,3.0 \%)$. Of the patients prescribed statins $(\mathrm{n}=4802)$, high-dose statins (atorvastatin $>20 \mathrm{mg}$ /day or rosuvastatin $>10 \mathrm{mg} /$ day $)^{8}$ were in $610(12.7 \%)$, moderate dose (atorvastatin $10-20 \mathrm{mg} /$ day or rosuvastatin $5-10 \mathrm{mg} /$ day) ${ }^{8}$ in $4100(85.4 \%)$ and low-dose (atorvastatin $<10 \mathrm{mg} /$ day, rosuvastatin $<5 \mathrm{mg} /$ day $)^{8}$ in $92(1.9 \%$; table 2). Use of high-dose statins was not significantly different in low-risk $(13.5 \%)$, medium-risk $(11.8 \%)$, or high-risk $(14.5 \%)$ patient groups (figure 2 ).

\section{DISCUSSION}

This multisite prescription audit and clinical study shows that statins are prescribed in $<60 \%$ of clinic-based patients with type 2 diabetes in India. High-dose statins, which are recommended in all the patients with 
Table 2 Prescription audit of drug therapies in the study cohort

\begin{tabular}{|c|c|c|c|c|c|}
\hline Variable & $\begin{array}{l}\text { Numbers with data } \\
\text { Total, men/women }\end{array}$ & $\begin{array}{l}\text { Total } \\
(\mathrm{N}=8699)\end{array}$ & $\begin{array}{l}\text { Men } \\
(\mathrm{N}=5292)\end{array}$ & $\begin{array}{l}\text { Women } \\
(\mathrm{N}=3407)\end{array}$ & $\begin{array}{l}\chi^{2} \text { test } p \text { value } \\
\text { (male/female } \\
\text { differences) }\end{array}$ \\
\hline \multicolumn{6}{|l|}{ Antidiabetes drugs } \\
\hline Insulin & $5023,3053 / 1970$ & $794(15.8)$ & $513(16.8)$ & $281(14.2)$ & 0.016 \\
\hline Oral antidiabetics & $8699,5292 / 3407$ & $4229(84.2)$ & $2772(90.8)$ & 1457 (73.9) & $<0.001$ \\
\hline \multicolumn{6}{|l|}{ Antihypertensive and other drugs } \\
\hline Renin angiotensin system blockers & $8699,5292 / 3407$ & 3169 (36.4) & $1897(35.8)$ & $1272(37.3)$ & 0.159 \\
\hline$\beta$-blockers & $6258,3898 / 2360$ & $1726(27.6)$ & $1060(27.2)$ & 666 (28.2) & $<0.001$ \\
\hline Calcium channel blockers & $4636,2820 / 1816$ & $1100(23.7)$ & $601(21.3)$ & 499 (27.5) & $<0.001$ \\
\hline Diuretics & $4515,2733 / 1782$ & $1438(31.8)$ & $815(29.8)$ & 623 (34.9) & $<0.001$ \\
\hline Antiplatelets & $6229,4515 / 2733$ & 2073 (33.3) & $1332(29.5)$ & $741(27.1)$ & 0.029 \\
\hline \multicolumn{6}{|l|}{ Lipid-lowering drugs } \\
\hline Statins & $8699,5292 / 3407$ & 4802 (55.2) & $3026(57.2)$ & $1776(52.1)$ & $<0.001$ \\
\hline Fibrates & $3546,2132 / 1414$ & $325(9.2)$ & $209(9.8)$ & $116(8.2)$ & 0.106 \\
\hline Lipid-lowering drugs at level of care & $8699,5292 / 3407$ & & & & \\
\hline Internists & $2301,1261 / 1040$ & 1227 (53.3) & $714(56.6)$ & $513(49.3)$ & $<0.001$ \\
\hline Diabetologists & $3299,2215 / 1084$ & $2126(64.4)$ & 1424 (64.3) & 702 (64.3) & 0.791 \\
\hline Endocrinologists & $3099,1816 / 1283$ & $1449(46.8)$ & $888(48.8)$ & $561(43.7)$ & 0.004 \\
\hline Statins in various risk groups & $8699,5292 / 3407$ & & & & \\
\hline Low risk & $1506,940 / 566$ & $855(56.8)$ & $539(57.3)$ & $316(55.8)$ & 0.567 \\
\hline Medium risk & $5424,3208 / 2216$ & $2920(53.8)$ & 1806 (56.3) & $1114(50.3)$ & $<0.001$ \\
\hline High risk & $1769,1144 / 625$ & $1027(58.0)$ & $681(59.5)$ & 346 (55.3) & 0.089 \\
\hline Statin types as percent of statin use & $4802,3026 / 1776$ & & & & \\
\hline Atorvastatin & & $3560(74.1)$ & $2252(74.4)$ & $1308(73.6)$ & 0.554 \\
\hline Rosuvastatin & & $1098(22.9)$ & $687(22.7)$ & $411(23.1)$ & 0.726 \\
\hline Other statins & & $144(3.0)$ & $87(2.9)$ & $57(3.2)$ & 0.511 \\
\hline Statins dosage as percent of statin use & $4802,3026 / 1776$ & & & & \\
\hline Low dose & & $92(1.9)$ & $54(1.8)$ & $38(2.1)$ & 0.386 \\
\hline Moderate dose & & $4100(85.4)$ & $2580(86.2)$ & $1520(85.6)$ & 0.758 \\
\hline High dose & & $610(12.7)$ & $392(13.0)$ & $218(12.3)$ & 0.497 \\
\hline
\end{tabular}

Numbers in parentheses are percent; renin angiotensin system blockers include ACE inhibitors and angiotensin receptor blockers.

Figure 1 Statins in men and women with diabetes at different age groups show lower prescriptions at younger age groups.

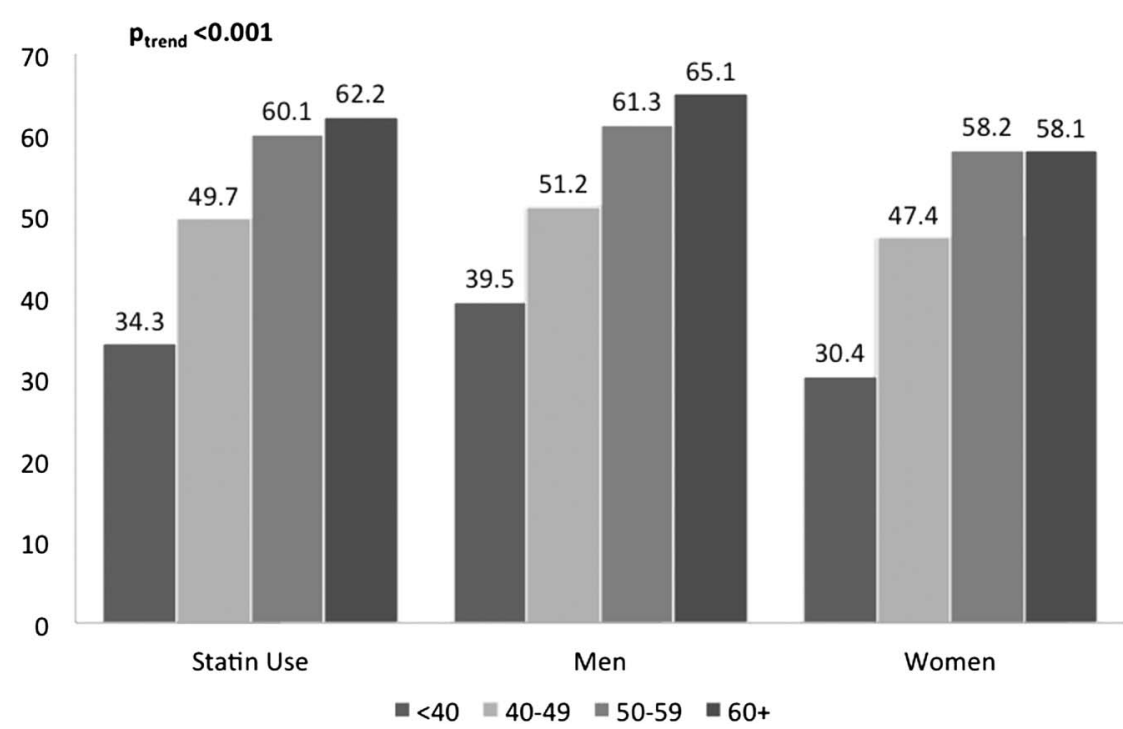

diabetes, $^{8}$ are prescribed in less than one-sixth of patients prescribed statins. Although the prescriptions of statins are significantly greater in high-risk patients with diabetes, the overall prescriptions of statins as well as high-dose statins are suboptimal and much lower than the guidelines. ${ }^{8}$
Diabetes has long been considered a cardiovascular risk equivalent. ${ }^{22}$ A Finnish study initially reported that patients with diabetes without manifest coronary heart disease had long-term (7-year) risk of events and mortality similar to patients without diabetes with manifest coronary heart disease. ${ }^{10}$ Subsequently, a number of 
Figure 2 No significant differences in prescriptions of low-dose, moderate-dose, and high-dose statins in low-risk, medium-risk, and high-risk patients with diabetes. Low-risk patients had no cardiovascular risk factors-smoking/tobacco, hypertension; medium-risk patients had diabetes with any one of the above risk factors; and high-risk patients had diabetes with clinical evidence of microvascular or macrovascular disease.

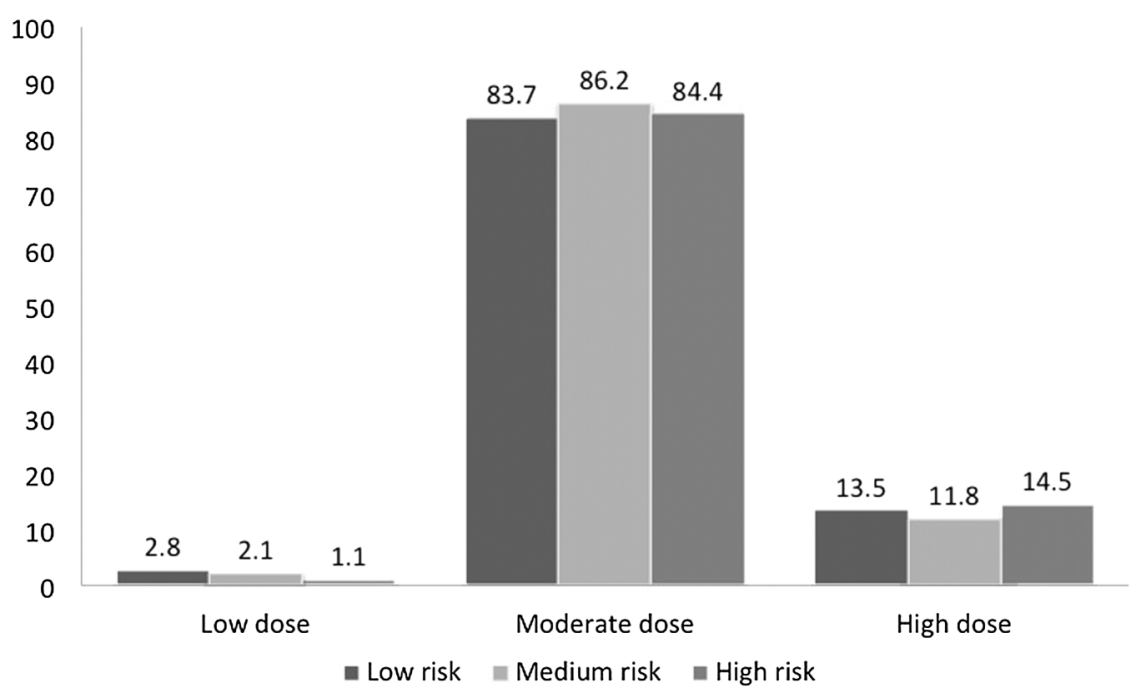

observational studies in Australia and Europe reported similar associations. ${ }^{11}{ }^{12}$ Based on these studies, as well as randomized controlled trials that demonstrated lowering of coronary risk with statins in patients with diabetes, ${ }^{23}$ the 2013 AHA/ACG guidelines on lipid management recommended that all patients with diabetes should receive high-dose statins irrespective of cholesterol levels. ${ }^{8}$

Registry-based studies in developed countries have reported increasing statin prescriptions in patients with type 2 diabetes since the guidelines endorsed their use. Prescriptions of statins in patients with diabetes have been reported in a few countries and examples include the Swedish National Diabetes Register, ${ }^{24}$ US National Health and Nutrition Evaluation Surveys (NHANES), ${ }^{25}$ British National Health Service (NHS), ${ }^{26}$ and Australian general practice, ${ }^{27}$ and the proportion of patients with diabetes prescribed statins varied from $25 \%$ to $65 \%$. Studies have also reported that the prescriptions are significantly greater in diabetologists' practices $(75 \%) .{ }^{26} 27$ Targets are more than $90 \% .{ }^{14}$ In our study, statins were prescribed in $55 \%$ of patients and, although, are lower than the Swedish and Australian registries and NHANES where these drugs are prescribed in $70-90 \%$ of patients, ${ }^{24} 2527$ but, are higher than the British NHS-Check programme. ${ }^{26}$ However, in our study, the high-dose statins are prescribed in less than a sixth of patients prescribed statins $(12.7 \%)$ and this is clearly suboptimal. Moreover, our study shows that statin prescriptions are much lower than optimal in patients with type 2 diabetes with known cardiovascular disease (highrisk group, figure 2). It has been recommended that all patients with coronary heart disease should be on a statin. ${ }^{8}$ We did not inquire regarding the intake of these drugs by the patients and this is a study limitation. It is well known that even after prescriptions, many patients do not take the statins and other medications for chronic diseases, ${ }^{29}$ especially in India. ${ }^{30} 31$
The study has multiple strengths as well as limitations. This is one of the largest contemporary registries on diabetes management from India and is especially relevant because it was performed after the publication of AHA/ACG Lipid Guidelines. ${ }^{8}$ Moreover, we have performed the study at clinics of qualified endocrinologists, as well as of diabetologists and internists who manage the majority of patients with diabetes in India. ${ }^{32}$ Limitations of the study include lower proportions of patients from the southern and eastern regions of the country and greater proportions from the northern and western regions, non-representation of secondary and primary care physicians who treat the majority of patients with diabetes in India, lack of systematic collection data on microvascular complications (especially renal disease), pragmatic risk classification of the patients which is different from the suggested criteria, ${ }^{33}$ and lack of patient-level consumption and adherence data. Other limitations include absence of baseline cholesterol levels of these patients to justify high-dose therapies and lack of data on the side effect profile of statins. Moreover, we did not perform a qualitative study to determine causes of low prescriptions of statins by

In conclusion, this study shows that prescriptions of statins in clinic-based patients with type 2 diabetes in India are suboptimal. Efforts to increase use of these drugs to all patients with diabetes to prevent cardiovascular complications are urgently required. These results are all the more important after the publication of the HOPE-3 study where statin use has been associated with a significant decrease in cardiovascular mortality and acute events in intermediate-risk patients including those with diabetes. ${ }^{34}$ Strategies to optimize prescriptions are better clinician awareness of guidelines and continuing medical education as well as periodic prescription audits and dissemination of results to improve quality of preventive care among patients with type 2 diabetes. physicians. 
Author affiliations

${ }^{1}$ Departments of Preventive Cardiology, Internal Medicine and Endocrinology, Eternal Heart Care Centre and Research Institute, Mount Sinai New York Affiliate, Jaipur, Rajasthan, India

${ }^{2}$ Research Unit, Fortis Escorts Hospital, Jaipur, Rajasthan, India

${ }^{3}$ Department of Endocrinology, Galaxy Specialty Centre, Jaipur, Rajasthan, India

${ }^{4}$ Department of Diabetes, Diabetes Care and Research Centre, Nagpur, Maharashtra, India

${ }^{5}$ Department of Diabetes, Madurai Medical College, Madurai, Tamil Nadu, India

${ }^{6}$ Department of Medicine, Assam Medical College, Dibrugarh, Assam, India

${ }^{7}$ Department of Medicine, BBD College of Dental Sciences, Lucknow, Uttar

Pradesh, India

${ }^{8}$ Department of Endocrinology, RNT Medical College, Udaipur, Rajasthan, India

${ }^{9}$ Department of Medicine, Satyam Hospital, Jodhpur, Rajasthan, India

Contributors RG conceived and designed the study, researched the data, and wrote and edited the manuscript. SL, KKS, SKS, SG, and RSK contributed to intellectual discussion and reviewed and edited the manuscript. SL, KKS, SKS, SG, AJA, BNM, AM, DCS, and ASM researched the data. RG is the guarantor.

Competing interests None declared.

Patient consent Obtained.

Ethics approval Institutional Ethics Committee, Eternal Heart Care Centre and Research Institute, Mount Sinai New York Affiliate, Jaipur, India.

Provenance and peer review Not commissioned; externally peer reviewed.

Data sharing statement No additional data are available.

Open Access This is an Open Access article distributed in accordance with the Creative Commons Attribution Non Commercial (CC BY-NC 4.0) license, which permits others to distribute, remix, adapt, build upon this work noncommercially, and license their derivative works on different terms, provided the original work is properly cited and the use is non-commercial. See: http:// creativecommons.org/licenses/by-nc/4.0/

\section{REFERENCES}

1. NCD Risk Factor Collaboration (NCD-RisC). Worldwide trends in diabetes since 1980: a pooled analysis of 751 population-based studies with 4.4 million participants. Lancet 2016;387:1513-30.

2. Chowdhury TA, Lasker SS. Complications and cardiovascular risk factors in South Asians and Europeans with early-onset type 2 diabetes. QJM 2002;95:241-6.

3. Misra A, Ramchandran A, Jayawardena R, et al. Diabetes in South Asians. Diabet Med 2014;31:1153-62.

4. Gupta A, Gupta R, Sharma KK, et al. Prevalence of diabetes and cardiovascular risk factors in middle-class urban populations in India. BMJ Open Diab Res Care 2014;2:e000048.

5. Deepa M, Bhansali A, Anjana RM, et al. Knowledge and awareness of diabetes in urban and rural India: the Indian Council of Medical Research India Diabetes Study (Phase I): Indian Council of Medical Research India Diabetes 4. Indian J Endocrinol Metab 2014:18:379-85.

6. Gupta R, Sharma KK, Gupta BK, et al. Education status related disparities in awareness, treatment and control of cardiovascular risk factors in India. BMJ Heart Asia 2015;7:1-6.

7. Sattar N, Gill JMR. Type 2 diabetes in migrant South Asians: mechanisms, mitigation and management. Lancet Diab Endocrinol 2015;3:1004-16.

8. Stone NJ, Robinson JG, Lichtenstein $\mathrm{AH}$, et al, American College of Cardiology/American Heart Association Task Force on Practice Guidelines. 2013 ACC/AHA guideline on the treatment of blood cholesterol to reduce atherosclerotic cardiovascular risk in adults: a report of the American College of Cardiology/American Heart Association task force on practice guidelines. Circulation 2014;129: S1-45.

9. Stamler J, Vaccaro O, Neaton JD, et al. Diabetes, other risk factors, and 12-yr cardiovascular mortality for men screened in the Multiple Risk Factor Intervention Trial. Diabetes Care 1993;16:434-44.
10. Haffner SM, Lehto S, Ronnenaa T, et al. Mortality from coronary heart disease in subjects with type 2 diabetes and in non-diabetic subjects with and without prior myocardial infarction. N Engl J Med 1998;339:229-34.

11. Barr EL, Zimmet PZ, Welborn TA, et al. Risk of cardiovascular and all-cause mortality in individuals with diabetes mellitus, impaired fasting glucose, and impaired glucose tolerance: the Australian Diabetes, Obesity, and Lifestyle Study (AusDiab). Circulation 2007;116:151-7.

12. Rana JS. Is diabetes really a CHD risk equivalent? http://www.acc. org/latest-in-cardiology/articles/2017/04/12/13/40/ is-diabetes-really-a-chd-risk-equivalent?wt.mc_id=twitter (accessed 1 Mar 2016)

13. Reiner Z, Catapano AL, De Backer G, et al, European Association for Cardiovascular Prevention and Rehabilitation, ESC Committee for Practice Guidelines (CPG) 2008-2010 and 2010-2012 Committees. ESC/EAS Guidelines for the management of dyslipidaemias: the Task Force for the management of dyslipidaemias of the European Society of Cardiology (ESC) and the European Atherosclerosis Society (EAS). Eur Heart $J$ 2011;32:1769-818.

14. Handelsman $\mathrm{Y}$, Bloomgarden ZT, Grunberger G, et al. American association of clinical endocrinologists and American College of Endocrinology - clinical practice guidelines for developing a diabetes mellitus comprehensive care plan-2015. Endocr Pract 2015;21 (Suppl 1):1-87.

15. Fox CS, Golden SH, Anderson C, et al, American Heart Association Diabetes Committee of the Council on Lifestyle and Cardiometabolic Health, Council on Clinical Cardiology Council on Cardiovascular and Stroke Nursing, et al. Update on the prevention of cardiovascular disease in adults with type-2 diabetes mellitus in light of recent evidence: a scientific statement from the American Heart Association and the American Diabetes Association. Diabetes Care 2015;38:1777-803.

16. Eliasson B, Svensson AM, Miftaraj M, et al. Clinical use and effectiveness of lipid lowering therapies in diabetes mellitus-an observational study from the Swedish National Diabetes Register. PLOS ONE 2011;6:e18744.

17. Raheja BS, Kapur A, Bhoraskar A, et al. DiabCare Asia-India Study: diabetes care in India-current status. J Assoc Physicians India 2001;49:717-22.

18. Goyal P, Sharma G, Bal BS, et al. Prospective, noninterventional, uncontrolled, open-chart, pharmacoepidemiologic study of prescribing patterns for lipid-lowering drugs at a tertiary care teaching hospital in North India. Clin Ther 2002;24:2064-76.

19. Nagpal J, Bhartia A. Quality of diabetes care in the middle and high income group populace: the Delhi Diabetes Community (DEDICOM) Survey. Diabetes Care 2006;29:2341-8.

20. Sharma N, Sharma SK, Maheshwari VD, et al. Association of low educational status with microvascular complications in type 2 diabetes: Jaipur Diabetes Registry-1. Indian J Endocrinol Metab. 2015;19:327-32.

21. Joshi SR. Diabetes care in India. Ann Global Health 2015;81:830-8.

22. Grundy SM, Benjamin IJ, Burke GL, et al. Diabetes and cardiovascular disease: a statement for healthcare professionals from the American Heart Association. Circulation 1999;100:1134-46.

23. Baigent C, Blackwell L, Emberson J, et al, Cholesterol Treatment Trialists' (CTT) Collaboration. Efficacy and safety of more intensive lowering of LDL cholesterol: a meta-analysis of data from 170000 participants in 26 randomised trials. Lancet 2010;376:1670-81.

24. Gudbjörnsdottir S, Eeg-Olofsson K, Cederholm J, et al. Swedish National Diabetes Register (NDR). Risk factor control in patients with Type 2 diabetes and coronary heart disease: findings from the Swedish National Diabetes Register (NDR). Diabet Med 2009;26:53-60.

25. Mann DM, Woodward M, Ye F, et al. Trends in medication use among US adults with diabetes mellitus: glycemic control at the expense of controlling cardiovascular risk factors. Arch Intern Med 2009;169:1718-20.

26. Chang KC, Soljak M, Lee JT, et al. Coverage of a national cardiovascular risk assessment and management programme (NHS Health Check): retrospective database study. Prev Med 2015;78:1-8.

27. Jiwa $M$, Meng $X$, Sriram D, et al. The management of Type 2 diabetes: a survey of Australian general practitioners. Diabetes Res Clin Pract 2012;95:326-32.

28. Smith SC, Benjamin EJ, Bonow RO, et al. AHA/ACC secondary prevention and risk reduction therapy for patients with coronary and other atherosclerotic vascular disease: 2011 update. J Am Coll Cardiol 2011;58:2432-46. 
29. Osterberg L, Blaschke T. Adherence to medication. N Engl J Med 2005;353:487-97.

30. Choudhry NK, Dugani SB, Shrank WH, et al. Despite increased use and sales of statins in India, per capita prescription rates remain far below high-income countries. Health Affairs 2014;33:273-82.

31. Xavier D, Gupta R, Sigamani A, et al. Community health worker based intervention for adherence to medications and lifestyle modifications after acute coronary syndrome: a randomized controlled trial. Lancet Diab Endocrinol 2016;4:244-53.
32. Sharma KK, Gupta R, Agrawal A, et al. Low use of statins and other coronary secondary prevention therapies in primary and secondary care in India. Vasc Health Risk Manag 2009;5:1007-14.

33. Russel KG, Rosenzweig J. Improving outcomes for patients with diabetes using Joslin Diabetes Center's registry and risk stratification system. J Health Informat Manag 2007;21:26-33.

34. Yusuf S, Bosch J, Dagenias G, et al, HOPE-3 Investigators. Cholesterol lowering in intermediate risk persons without cardiovascular disease. N Engl J Med 2016;374:2021-31. 